\title{
The Multidimensional Structure of Interest
}

\author{
Jael Draijer ${ }^{\mathrm{a}}$, Arthur Bakker ${ }^{\mathrm{a}}$, Esther Slot $^{\mathrm{a}}$ \& Sanne Akkerman ${ }^{\mathrm{a}}$
}

aUtrecht University, The Netherlands

Article received 21 October 2019 / Article revised 7 May 2020 / Accepted 17 May / Available online 15 June

\begin{abstract}
There is increasing attention for interest as a powerful, complex, and integrative construct, ranging in appearance from entirely momentary states of interest to longer-term interest pursuits. Developmental models have shown how these situational interests can develop into individual interests over time. As such, these models have helped to integrate more or less separate research traditions and focus the attention of the field more on the developmental dynamics. This, however, also raises subsequent questions, one being how development can be understood in terms of interest structure. The developmental models seem to suggest that development occurs roughly along the line of six dimensions, which we summarize as the dimensions of historicity, value, agency, frequency, intensity, and mastery. Using an experience sampling method that was implemented in a smartphone application, we prompted 94 adolescents aged 13 to 16 (60\% female) to rate each interest they experienced during two weeks on these six dimensions. A latent profile analysis on 1247 interests showed six distinct multidimensional patterns, indicating both a homogeneous and heterogeneous structure of interest. Four homogeneous patterns were indicated by more or less equal levels on all six dimensions in varying degrees, and contained $86 \%$ of the interests. Two heterogeneous patterns were found, describing variations of interest that are interpreted and discussed. These results endorse the complexity of the construct of interest and provide suggestions for identifying different manifestations of interest.
\end{abstract}

Keywords: interest; situational interest; individual interest; structure of interest; latent profile analysis 


\section{Introduction}

Interest has for long been seen as a powerful basis for learning and good education. More than a century ago, interest was already seen as a guarantee for effortless attention (Arnold, 1906; Dewey, 1913) and research over the years has shown that interest goes together with motivation to further engage in certain topics or activities, relates strongly to academic achievement across subject areas, school types, and age groups (Ainley, Hidi, \& Berndorff, 2002; Harackiewicz, Durik, Barron, LinnenbrinkGarcia, \& Tauer, 2008; Hidi \& Renninger, 2016; Schiefele, Krapp, \& Winteler, 1992) and to more sustainable curriculum choices and career decisions (Harackiewicz, Barron, Tauer, \& Elliot, 2002; Harackiewicz et al., 2008; Köller, Baumert, \& Schnabel, 2001). Currently, interest is appreciated particularly because it generates a learning process that appears natural and intrinsic to the person, and therefore fits with new models of education that depart from person-centered, life-wide and connected learning approaches (e.g., Barron, 2006; Ito et al., 2018; Walkington, 2013). This new appreciation has sparked research focusing on how interests may be evoked (e.g., Renninger, Bachrach, \& Hidi, 2019) and sustained in education (Harackiewicz et al., 2008; Hedges, 2019). Additionally, recent research has shown that also interests outside the school context can be catalysts for meaningful learning processes, with the potential to develop considerable knowledge and skills (Ito et al., 2018; Krapp, 2002; Renninger \& Hidi, 2016). Moreover, out-of-school interests can be of equal value to students in making study and career choices, an interest in gaming for example leading a student to consider choosing Computer Science (Erstad \& Silseth, 2019; Holmegaard, 2015, Vulperhorst, van der Rijst, \& Akkerman, 2020). Recognition of the powerful role of out-of-school interests has also generated educational research on how to involve students' existing interests into education (e.g., Hinton \& Kern, 1999; Reber, Canning, \& Harackiewicz, 2018).

Besides being powerful, interest is also a complex construct; it integrates cognition, motivation and affect (Hidi \& Renninger, 2006, Renninger \& Leckrone, 1991; Sachisthal et al., 2018; Schiefele \& Rheinberg, 1997) in a person's perception of and preference to engage with a specific object of interest (Arnold, 1906; Krapp, 2002). Moreover, key scholars have proposed that interests may manifest in different ways, ranging from a relatively fleeting person-object relation, referred to as situational interest, to a long-lasting predisposition towards specific person-object relations, referred to as individual interest (Krapp, Hidi, \& Renninger, 1992). During the last two decades scholars have attempted to capture the spectrum between these two extreme manifestations of interest, proposing developmental models to define the shades in between (e.g., Hidi \& Renninger, 2006; Krapp, 2002). The current study aims to contribute to the understanding of this spectrum by conducting a more detailed investigation of the structure of interest in various manifestations, so as to advance our understanding of interest as well as provide a more nuanced basis for how to evoke and sustain interests in educational settings and materials. In the following we first describe how key scholars have theorized different manifestations of interests and what appears as underlying dimensions of this development.

\subsection{Manifestations of interest}

The conceptualization of interest shows a long tradition with increasing nuance in how interest can be manifested (Krapp, 2002). The two aforementioned manifestations of interest have long been regarded and studied as independent constructs, with one tradition focusing on individual interest (e.g., Dewey, 1913; Strong, 1927) and one focusing on situational interest (e.g., Hidi \& Baird, 1986). However, Krapp (2002) proposed that situational interests could under the right conditions develop into individual interests, as such unifying them as two kinds of the same phenomenon. He proposed a threephase developmental model using two phases of situational interest (catch and hold) earlier defined by Mitchell (1993). Hidi and Renninger (2006) extended this to a four-phase model of interest development, splitting up individual interest into two phases referred to as emerging and well-developed individual interest. Most distinctive in these four phases is the increasing duration and strength of interest as it progresses.

The three- and four-phase models led the field to recognize the wide variation in manifestations of interest, but more detailed descriptions of these manifestations are warranted. Descriptions of the four 
phases in the literature suggest multiple indicators of interest (e.g., value, knowledge) underlying all phases. Each subsequent phase is described to be mainly characterized by higher levels of these indicators (e.g., value builds up with each subsequent phase), yet this does not seem to apply to every indicator. For instance, when describing the role of external support in interest development, Hidi and Renninger $(2006,2011)$ emphasize that both emerging and well-developed individual interests are "typically but not exclusively self-generated" (2006, p. 115) and might still benefit from external support. These various descriptions are relevant as they suggest there might be more complexity in the dimensional structure of interest: High levels on one dimension may not necessarily indicate high levels on other dimensions. In the current study we aim to clarify this multidimensionality of the construct of interest. First, we look at the literature of abovementioned key scholars in developmental interest theories (i.e. Suzanne Hidi, Ann Renninger, and Andreas Krapp) to identify the dimensions that seem key in describing different manifestations of interests. These dimensions are then used to measure a diverse set of interests and the relations between the dimensions are examined.

\subsection{Dimensions of interest}

To identify key dimensions of interests we searched for indicators that are suggested to vary across and distinguish between interests. Some indicators of interest, like focused attention, are described to be always present to a similar degree (Dewey, 1913; Krapp et al., 1992; Schiefele, 2009) and are therefore not key to distinguish manifestations of different interests. Using the work of aforementioned key scholars, we arrived at six dimensions which can be considered continuous dimensions by means of which to differentiate diverse manifestations of interests.

\subsubsection{Historicity}

The first of these dimensions is the time a person has engaged in an interest. Triggered situational interests are short-term (Hidi \& Renninger, 2006), whereas individual interests are assumed to be relatively enduring (Krapp et al., 1992) and can persist over the course of years. The term historicity is used as a counterpart of novelty and signifies the quality of being historical or long-term and thus already meaningful to a person in some way (Bruner, 1990). The historicity of an interest can therefore be seen as a dimension underlying interest, which can be used to distinguish between interests in different manifestations.

\subsubsection{Agency}

The degree to which an interest is internally or externally triggered and maintained is a second characteristic that can be used to distinguish between different manifestations of interest. Whereas a situational interest is considered to be largely externally triggered and maintained, an individual interest is regarded as mainly internally managed and pursued by the person (Krapp et al., 1992). Several terms have been employed to refer to this aspect of internal management, for example external support needed as opposed to self-generated (Hidi \& Renninger, 2006), voluntary and independent engagement (Renninger \& Hidi, 2016). In the current study we employ the term agency to denote the extent to which a person is the agent of their own interest, both in triggering and pursuing the interest.

\subsubsection{Value}

High value attributed to the object of interest is often taken as an indicator of an individual interest (Hidi \& Renninger, 2006; Krapp, 1999). Value refers to the personal significance of the object of interest because of various possible reasons, for example because it is considered relevant to a person's enjoyment, development or future goals (Krapp, 2002). Hidi and Renninger (2006) have used the concept of stored value which builds up over time as an interest moves from situational to individual phases.

\subsubsection{Frequency}

An additional indicator of the distinction between different interests is the frequency of engagement. It is assumed that a well-developed individual interest is more frequently engaged with than a situational interest (Renninger \& Hidi, 2016), as persons with an individual interest actively seek 
repeated reengagement with this interest (Hidi \& Renninger, 2006). As engagement in a situational interest is externally triggered, it is assumed that the frequency of engagement for these interests is lower.

\subsubsection{Intensity}

Even though every interest is characterized by focused attention, engagement in some interests is more intense than engagement in others (Renninger \& Hidi, 2016). Especially with well-developed interests, engagement is characterized as more intense concentration on what one is doing, a loss of selfawareness and distortion of the perception of time, which is also called flow (Nakamura \& Csikszentmihalyi, 2014; Renninger \& Hidi, 2016). As flow is often regarded as a specific state that requires high perception of skills and challenge only, we refer here to intensity of engagement as a continuous dimension of interest.

\subsubsection{Mastery}

Finally, interest is closely associated to gaining knowledge or expertise about the interest related contents and activities, in other words gaining mastery of the object. Key scholars have taken high levels or depth of knowledge as a characteristic of individual interest (Hidi \& Renninger, 2006; Renninger, 2000; Renninger \& Su, 2019), whereas other scholars have stressed the possibility of combinations of high interest (as indicated by high attributed value) and low knowledge (Alexander et al., 1994; Tobias, 1994). In the current study we chose to include mastery as a potential dimension of interest, allowing to explore how it relates to other dimensions in describing the structure of interest.

\subsection{Current study}

Following from the above, historicity, value, agency, frequency of engagement, intensity, and mastery can all be seen as distinctive, yet continuous dimensions by means of which to differentiate interests with diverse dimensional structures. Every interest can be considered as positioned somewhere on these dimensions at a particular moment in time. Although consistent with descriptions and developmental models of situational and individual interests (Hidi \& Renninger, 2006; Krapp, 2002), previous literature has not given insight into the way these dimensions are associated, thereby implying that these dimensions manifest themselves homogeneously. This would mean that when measuring the six dimensions for various interests, the dimensions are always related in roughly the same way (high value also means high mastery and high flow, etc.). A more heterogeneous structure of interest would be indicated by distinct patterns of association between the dimensions for different interests, for example by a cluster of interests that show low mastery but high value, whereas another cluster of interests perhaps shows reversed relations between these dimensions.

In the current study we aim to clarify the structure of interest by examining the relations between these multiple dimensions using a bottom-up approach. Accordingly, the research question is: What dimensional structure underlies the construct of interest in terms of the dimensions historicity, value, agency, frequency, intensity, and mastery? Insight into the structure of interest can aid methodological, theoretical and practical understanding of this complex construct. If the structure of interest points towards homogeneity, it can be measured efficiently by focusing on a limited set of dimensions; if there is evidence for a multidimensional structure this will need to be reflected in interest measurements. A more detailed characterization of different manifestations of interests can aid researchers and educators in searching for ways to trigger situational interest and stimulate individual interests in school subjects, disciplines and future professions. For example, if this research provides evidence for different manifestations of novel ("situational") interests, further research could study the different ways in which these manifestations would develop and can be aided to sustain over time. 


\section{Methods}

As the aim of the current study is to explore the construct of interest, we measured all possible daily-life interests without limiting to certain content domains. To this end the current study employs an experience sampling method (ESM): a research methodology in which participants receive signals to answer questions about their situated experiences at set or randomized points in time (Csikszentmihalyi, Larson, \& Prescott, 1977). The study was approved by the Ethics Committee of the Faculty of Social and Behavioural Sciences of Utrecht University.

\subsection{Participants}

The participants of this study were 94 high school students from four different Dutch schools, aged 13 to 16 years old $(M=14.53, S D=0.45)$, of which $60 \%$ were girls. The schools were recruited through advertisements in educational journals for practitioners. Within each school all ninth graders were invited to participate, and 145 students volunteered ( $20 \%$ of all ninth graders). A stratified sampling strategy based on class and gender was used to select the final sample. The students were offered financial compensation (€25) for taking part in the study and their parents were asked to sign permission forms.

\subsection{Procedure}

ESM is used to study participants in their natural environments through self-report and generally provides a more accurate representation of reality (Csikszentmihalyi \& Larson, 2014). In the current study ESM was implemented in a smartphone application, named inTin, to study all interests that high school students experience during their daily lives (Akkerman \& Bakker, 2012-2014; Akkerman \& Bakker, 2019). The participants used inTin for two consecutive weeks in November 2015. They received a 1.5-hour instructional briefing prior to the data collection, during which they discussed what interests are and how to use the application. Additionally, they practiced with filling in the application and were stimulated to ask questions.

Table 1

The Six Semantic Scales as Used in inTin, in Dutch (Italicized) and Translated to English

\begin{tabular}{|c|c|}
\hline Scale & $\begin{array}{l}\text { This interest: } \\
\text { Deze interesse: }\end{array}$ \\
\hline Historicity & $\begin{array}{l}\begin{array}{l}\text { is new to me ....................................... I have had a long time } \\
\text { is nieuw } \\
\text { heb ik al lang }\end{array}\end{array}$ \\
\hline Value & is not important to me ............................. is very important to me \\
\hline Agency & $\begin{array}{l}\text { is niet belangrijk voor mij } \\
\text { comes from others .............................. comes from within me } \\
\text { komt vooral vanuit anderen }\end{array}$ \\
\hline Frequency & $\begin{array}{l}\text { I rarely do ............................................. I do very often } \\
\text { doe ik zelden } \\
\text { doe ik heel vaak }\end{array}$ \\
\hline Intensity & 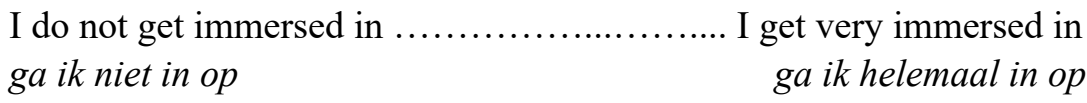 \\
\hline Mastery & $\begin{array}{l}\text { I am a beginner .......................................... I am an expert } \\
\text { beginnersniveau }\end{array}$ \\
\hline
\end{tabular}




\subsection{Instrument}

The application inTin was used to record participants' interests. At the start of the data collection period, users were asked to enter all their existing interests into the application. The participants were free to give any name to their interests, without pre-determined categories. This procedure resulted in a list of the topics and activities that the adolescents considered their interests. The dimensions underlying the construct of interest were presented to participants when they added an interest to the application. The six dimensions were formulated as semantic scales (Table 1) and participants had to rate their interest on sliders with scores from 0 to 100 . The starting point of each slider was at 50, participants had to touch and move each slider to be able to continue.

During the two weeks of data collection, inTin prompted users every two waking hours (including school hours) to report whether they had engaged with an interest in the past hours and, if so, users were asked several questions on how they engaged with this interest (this moment-to-moment data is not used in the current study). Users could either select the interests in their existing list, or add a new interest to the list. If a new interest was added, users were asked to rate this interest on the six scales as well, thus resulting in a final list of their existing interests and all interests they encountered during the two-week period.

To gain some insight into the interests that were reported in this study, we coded the content domains of the interests using four categories: School \& Work, Leisure \& Social, Maintenance, and Self \& World. The first category contained all interests that participants reported in the school domain, like school courses and topics, within-school projects (e.g., school musical) and jobs. Leisure \& Social contains interests in the leisure domain, such as hobbies, sports, media, and social activities. Maintenance contains interests that are considered to be part of daily routines, such as eating, cooking, and cleaning. The Self \& World category consists of interests in public issues, religion, and future plans (e.g., career choices). Cohen's kappa was calculated for $10 \%$ of the data (125 interests) to determine interrater reliability. Results indicated strong agreement between the two coders, $\kappa=.87, p<.001$.

\subsection{Data analysis}

In total 1247 interests were added to the application by the participants, with an average of 13 interests per student. On average, each interest was engaged with three times within the two weeks of data collection. During data collection some technical difficulties occurred, which resulted in missing interests for 26 students, ranging from 1 to 11 missing interests. No systematic mechanism could be found to explain why these interests were missing and it is unlikely that the missingness was related to the structure of the interests on the dimensions. As entire interests were missing, these were regarded as a form of unit nonresponse and data imputation was not applicable. To evaluate the impact of the participants with missing interests on the results, analyses described below were run with and without these participants. The results were robust in the sense that the difference between including or excluding these participants was very small: The same profile solution was chosen as best representing the data, and the resulting profiles were almost identical in shape (the dimension-means in each profile differing by 0.14 on average) and size (maximum 2 percent difference). Therefore, we decided not to exclude any participants and included everyone in the final analyses.

All analyses were conducted with Mplus 7.2 (Muthén \& Muthén, 2015). Since the research question of this study was concerned with estimating parameters at the interest-level and not the individual level, we chose not to conduct multi-level analyses. However, as interests were nested within individuals, all analyses used in this study took nesting and non-independence of observations into account by adjusting standard errors and chi-square tests of model fit (TYPE=COMPLEX in Mplus; Muthén \& Muthén, 2015).

An explorative latent profile analysis (LPA; Lazarsfeld \& Henry, 1968) was conducted on the 1247 interests to assign interests to categories based on empirically distinctive patterns of scores on the six semantic scales. These categories of interests with a similar pattern are called profiles. We ran oneto eight-profile models and compared these to identify which of them described the data best. If a one- 
profile model would suit the data best, that would indicate a homogeneous structure of interest; if one of the multi-profile models would describe the data best, this would indicate a more heterogeneous structure in which dimensions are in interplay to form distinct multidimensional patterns. The model is displayed in Figure 1. The variances were restricted to be equal across profiles conform the Mplus default, since our hypothesis is primarily focused on differences between different profile solutions and the shape of the final solution. In addition, assessing variance differences between groups would have made the interpretation of the results unnecessarily convoluted and testing any hypotheses regarding variances may require getting a larger sample.

To determine the model that would best represent the data, we used the criteria advocated by Meeus, Van de Schoot, Keijsers, Schwartz, and Branje (2010), with the exception of using BLRT (bootstrap Lo-Mendel-Rubin likelihood ratio test) as this is unsuitable to models with nested data. First, a solution with $k+1$ profiles should demonstrate better model fit than the previous solution of $k$ profiles, indicated by a lower Bayesian Information Criterion (BIC) value. In the current study we also include AIC and adjusted BIC. Second, in the chosen solution the profile separation should be reasonable and interests should be able to be assigned to a profile accurately, indicated by entropy level of minimally 0.70 . Third, the additional profile of a $k+1$ model should be a meaningful addition, and not a slight variation on one of the previously identified profiles. As recommended by Marsh, Lüdtke, Trautwein, and Morin (2009), the relation to theory, the nature of the groups and interpretation of the results are also taken into account when choosing the solution that makes most sense. Using Wald tests for equality of parameters on the LPA models (as recommended by Asparouhov \& Muthén, 2007), we evaluated whether each scale contributed to the distinction between profiles.

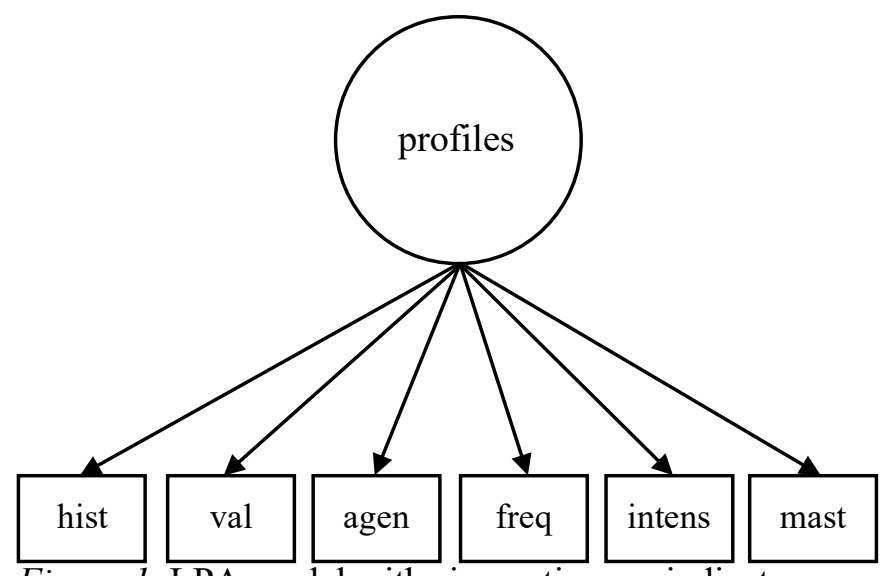

Figure 1. LPA model with six continuous indicators

\section{Results}

To study the multidimensional structure of interest, we first compared results of all LPAmodels. If applicable, we discuss the interest profiles of the chosen model regarding the profile patterns and the content domains of the interests in each profile.

\subsection{Latent profile analysis}

First we investigated the results of the LPA. The AIC, BIC and adjusted BIC decrease as the number of profiles increases (see Table 2). This indicates that every model with an additional profile is an improvement on the previous model. Entropy values are above .70 for all solutions, which indicates good profile separation and means that interests can be assigned to profiles accurately in all models. As model fit indices were not conclusive on the number of profiles in the data, we also looked at the additional value of the new profiles and profile interpretability (Marsh et al., 2009; Meeus et al., 2010). 
In Figure 2 it can be noted that from the seventh profile onwards no new theoretically meaningful profiles emerged. The seventh profile is a variation of the fourth profile: The pattern is similar with slightly higher values on the scales. Therefore, it does not represent a conceptually new category of interests. The eighth profile that emerged was hard to interpret and contained only 25 interests, and was therefore not deemed a relevant pattern. Because of these considerations we did not judge the seventh and eighth profile as extremely meaningful in this data and chose the six-profile model as most useful and valid in describing variations in the data at this time. The six-profile model met our criteria and showed distinctive profiles that we deemed interpretable, meaningful and interesting to further explore. We do however acknowledge that the fit indices are not conclusive and stress the importance of future research in exploring other possible variations of interest.

Looking at the shapes of the resulting profiles, it can be noted that the largest contrast is between the historicity dimension and the other five dimensions. As historicity cannot decrease over time for a certain interest, contrary to the other dimensions, it can be seen as the odd one out conceptually also. We therefore assessed whether the same results would be found if historicity was excluded from the analyses. The results of this analysis are displayed in the Appendix A and they also suggest a profile solution with both homogeneous and heterogeneous structures.

\subsection{Six-profile model}

The six-profile model contains four flat profiles, which we named according to their position (Figure 3A), and two irregular profiles which we named according to their shape (Figure 3B). All semantic scales contribute to the distinction between the profiles as indicated by the significant Wald statistics (Table 3). As a further assessment of validity, we checked the distribution of profiles across participants. A person's interests fall on average into 3.5 different profiles, which provides support that the multiple profiles are not subject to major individual differences.

For the sake of interpretation, profile membership is fixed in the remainder of the article (meaning that each interest is assigned to a profile by the highest posterior class-membership probability). 

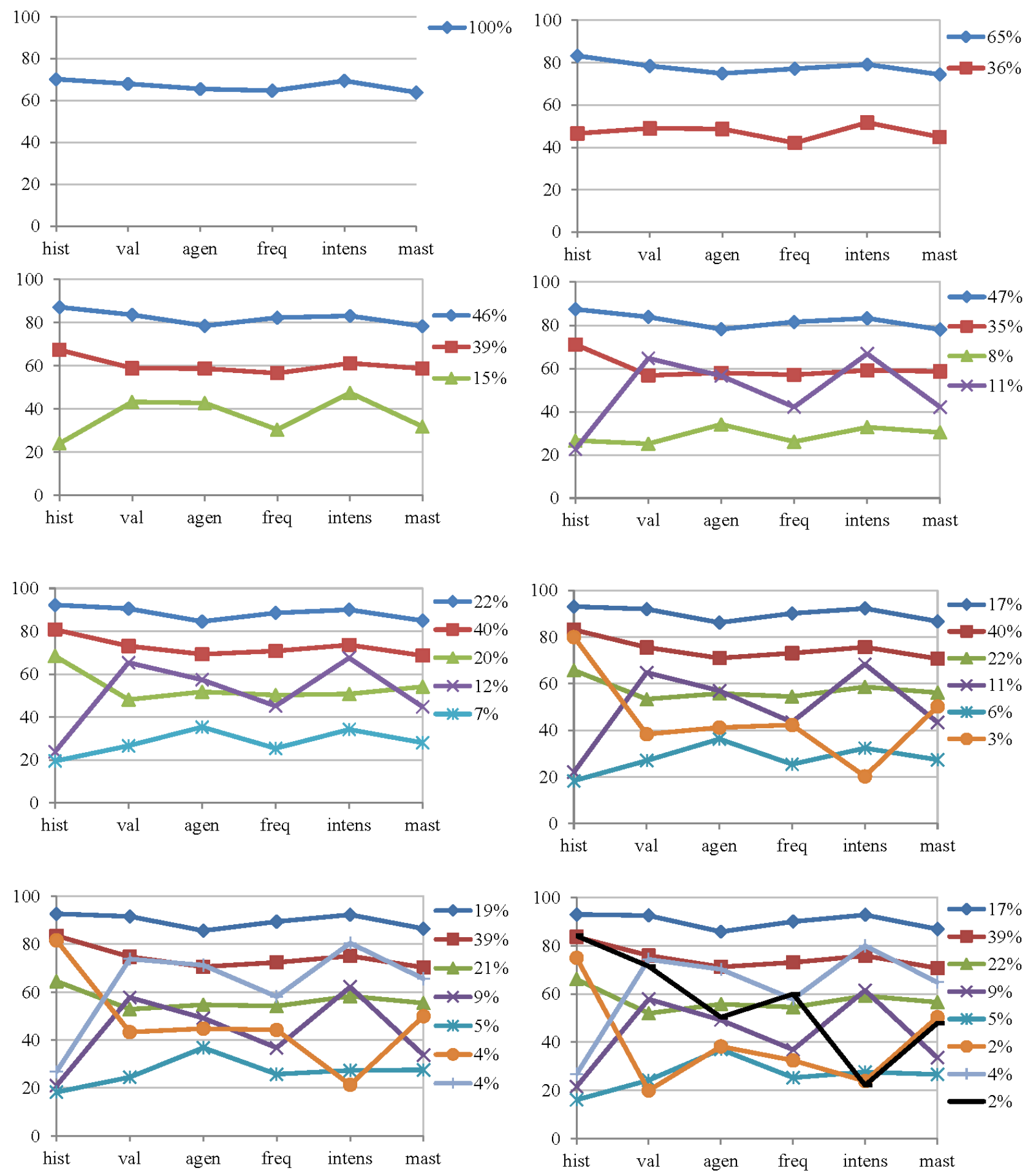

Figure 2. Distribution of the profiles across the six scales, for 1-profile to 8-profile solutions. 
Table 2

Log-Likelihood, Model Fit Indices and Entropy Measures for the 1-to 8-Profile Models $(N=1247)$.

\begin{tabular}{lllllllll}
\hline & 1-profile & 2-profile & 3-profile & 4-profile & 5-profile & 6-profile & 7-profile & 8-profile \\
& LPA & LPA & LPA & LPA & LPA & LPA & LPA & LPA \\
\hline LLH & -34567.838 & -33541.304 & -33281.001 & -33120.958 & -33031.837 & -32957.366 & -32899.300 & -32843.602 \\
AIC & 69159.677 & 67120.609 & 66614.001 & 66307.917 & 66143.673 & 66008.733 & 65906.601 & 65809.205 \\
BIC & 69221.219 & 67218.050 & 66747.342 & 66477.157 & 66348.813 & 66249.772 & 66183.540 & 66122.043 \\
Adj. BIC & 69183.101 & 67157.697 & 66664.754 & 66372.334 & 66221.755 & 66100.479 & 66012.011 & 65928.280 \\
Entropy & n/a & 0.832 & 0.796 & 0.844 & 0.783 & 0.799 & 0.814 & 0.833 \\
\hline
\end{tabular}

A

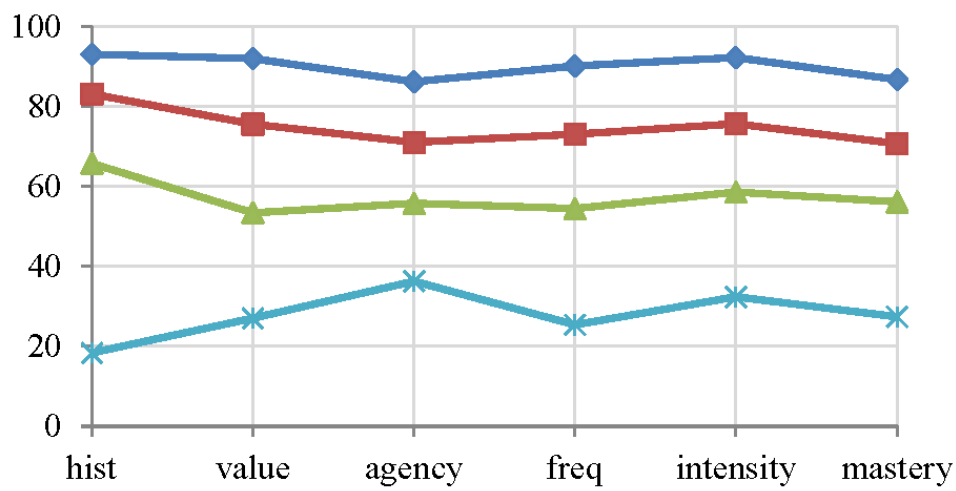

$\leadsto$ Top flat

$(17 \%)$

$\rightarrow-$ High flat

$(40 \%)$

$\rightarrow$ Middle flat

$(22 \%)$

*Low flat

$(6 \%)$

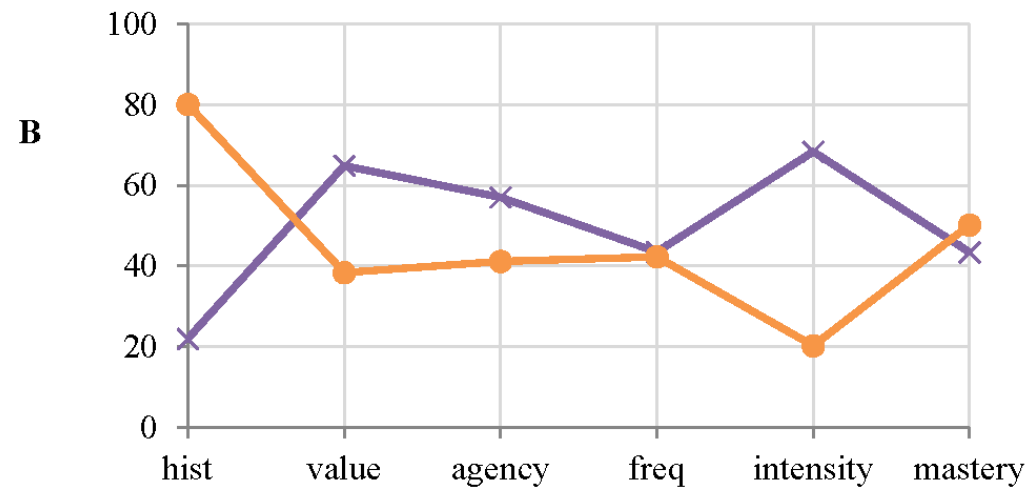

×Irregular M

$(11 \%)$

- Irregular W

(3\%)

Figure 3. Flat (A) and irregular (B) profiles in the six-profile solution.

Table 3

Means, Variances and Wald Test Statistic of the Semantic Scales in the 6-Profile Model

\begin{tabular}{|c|c|c|c|c|c|c|c|c|}
\hline \multirow[t]{2}{*}{ Scale } & \multicolumn{6}{|c|}{ Means } & \multirow[t]{2}{*}{ Variance } & \multirow[t]{2}{*}{ Wald $\chi^{2}$} \\
\hline & Top & High & Mid & Low & M & W & & \\
\hline Historicity & 93 & 83 & 65 & 18 & 22 & 80 & 193.26 & 1453.96* \\
\hline Value & 92 & 75 & 53 & 27 & 64 & 38 & 212.33 & $454.58 *$ \\
\hline Agency & 86 & 71 & 56 & 36 & 57 & 41 & 526.41 & $122.57^{*}$ \\
\hline Frequency & 90 & 73 & 54 & 25 & 44 & 42 & 324.36 & $425.20 *$ \\
\hline Intensity & 92 & 76 & 59 & 32 & 68 & 20 & 177.95 & $604.50 *$ \\
\hline Mastery & 87 & 71 & 56 & 27 & 43 & 50 & 277.83 & $259.06^{*}$ \\
\hline
\end{tabular}

Note. $^{*}=$ significant at $p<.001, \mathrm{df}=5$. 


\subsubsection{Flat profiles}

The four profiles with a horizontal pattern contain interests with a homogeneous structure: These interests were given approximately equal scores on all six dimensions. The top flat profile contains approximately $17 \%$ of the reported interests in the data and is indicated by a pattern of high scores on all scales. These interests were familiar to the participants and internally driven; they were valued highly and engaged in frequently. Participants reported that their engagement in these interests was intense and that they experienced mastery. The high flat profile has the same shape with slightly lower scores on all scales. This profile is the largest in the data and contains almost $40 \%$ of the interests. The middle flat profile is indicated by scores around 60 on all dimensions: These interests were rated lower than the first two profiles on the dimensions but have the same shape. The low flat profile contains interests that the participants rated very low on the six dimensions. These interests were reported to be new, not valued very highly, mostly controlled by others, not experienced very frequently, not intense and not mastered.

\subsubsection{Irregular profiles}

The two irregular shaped profiles contain interests with a heterogeneous structure. The irregular M-shaped profile (further abbreviated as M-profile) has a pattern of lower scores on self-reported historicity, frequency, and mastery, and higher scores on value, agency, and intensity. This profile thus indicates a group of interests that were quite new to participants, were not engaged in very often and were not mastered, but were regarded as quite important, intense, and internally controlled. The other distinctive pattern is the irregular W-shaped profile (further abbreviated as W-profile), which is indicated by very high scores on self-reported historicity and lower scores on the other items, especially on intensity of engagement. This profile contains interests that the participants reported they had had for a while, but were not valued very highly, not internally controlled, were not engaged in very frequently nor intensely, and were not mastered.

\subsubsection{Content domains}

To aid further interpretation of the multidimensional patterns, we categorized the interests according to content domain. This categorization serves to further describe the profiles and gain more understanding of their composition. Overall, the largest proportion of interests concerned Leisure \& Social interests (74\%), followed by School \& Work (16\%), Maintenance (8\%) and Self \& World (2\%). Figure 4 displays the proportions of interests within each category for every profile. Every profile contains interests of every content category.

The top flat profile contains mainly Leisure \& Social interests (88\%), as do the high flat profile $(82 \%)$ and the mid flat profile $(65 \%)$. The low flat profile mainly consists of both Leisure \& Social (46\%) and School \& Work (42\%) interests. A small amount of the interests in the flat profiles are coded as Maintenance (5-11\%) and Self \& World (1-6\%).

The irregular M-profile contains a large amount of Leisure \& Social (53\%) and School \& Work (34\%) interests. Of the interests in the M-profile, 9\% was coded as Self \& World interests. Notable amongst these are interests related to the terrorist attacks in Paris that took place right before the data collection in November 2015. The irregular W-profile consists mostly of Leisure \& Social interests (75\%). Notable amongst these are a large proportion of interests in watching TV (30\% of the interests in the W-profile). 


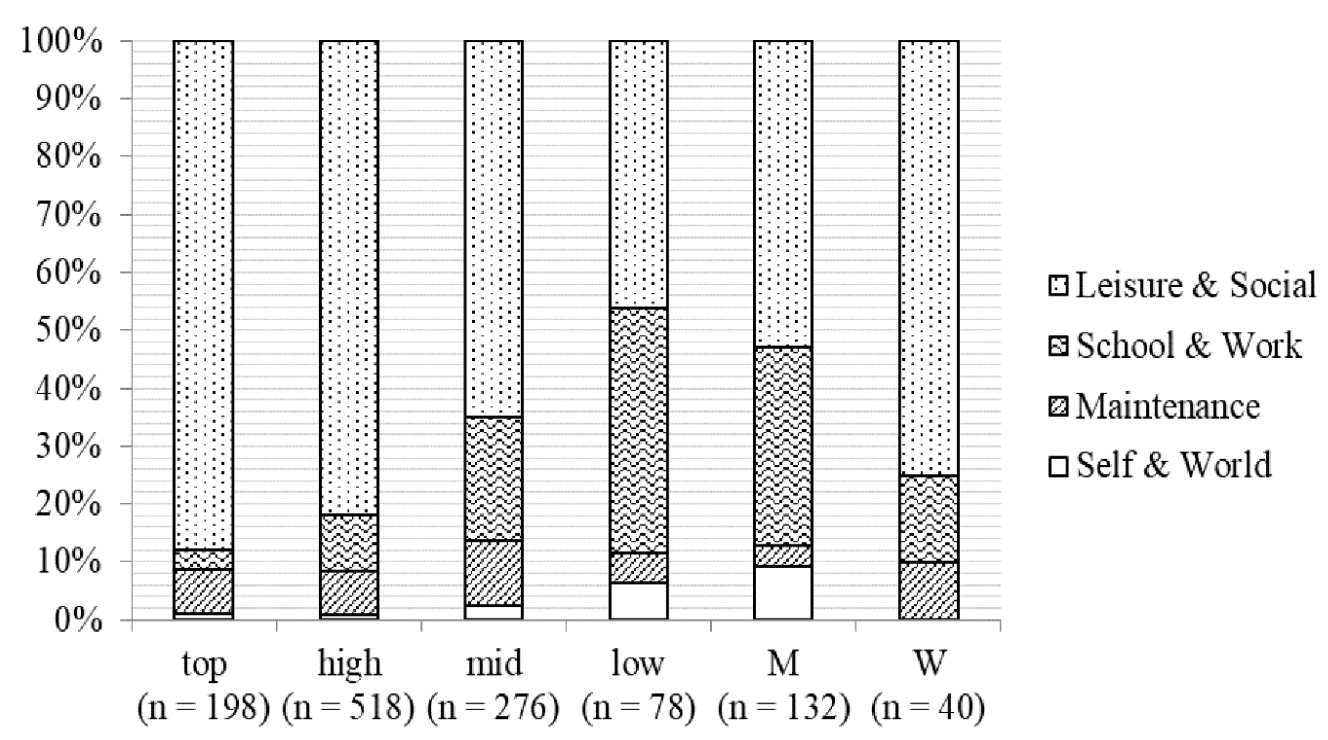

Figure 4. The proportion of School \& Work, Leisure \& Social, Maintenance, and Self \& World interests within one profile.

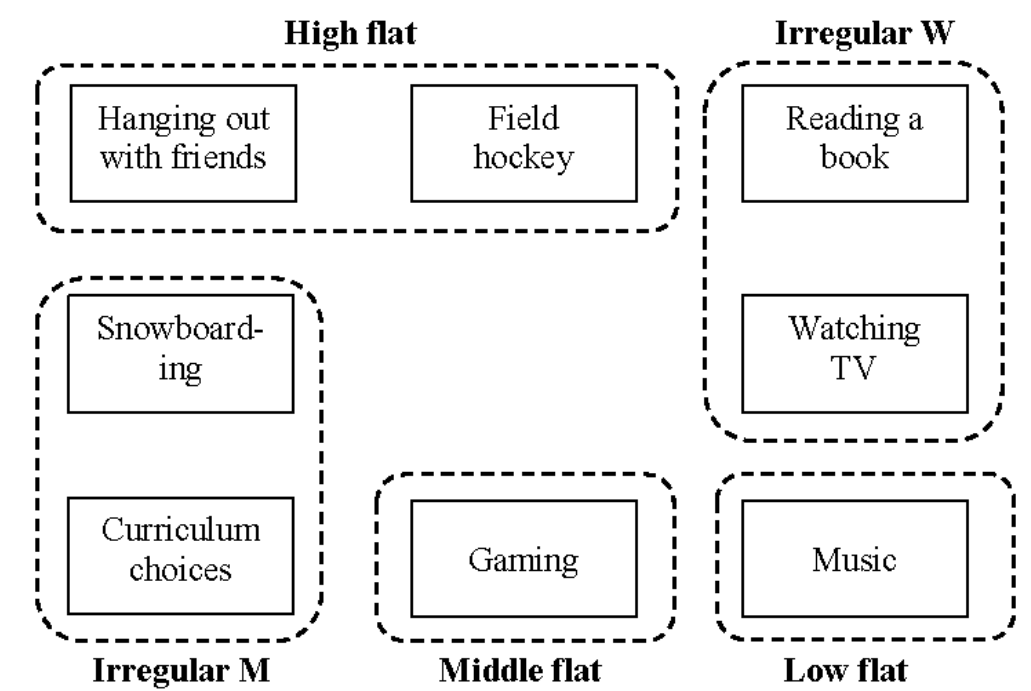

Figure 5. Interests of Tyler in each profile.

\subsection{Interest portrait}

To further illustrate the six profiles, we discuss the interests of one of the boys in the sample. Tyler is a 14-year old boy who reported interests that were representative for those in the total sample (Figure 5). Tyler reported no interests in the top flat profile. His interests in hanging out with friends and field hockey were assigned to the high flat profile based on the semantic scales: Their levels of value, agency, frequency, intensity and mastery are approximately equal. Tyler's interest in gaming was assigned to the middle flat profile: It shows the same pattern on the dimensions as the first two interests, but with lower scores. Compared to field hockey, Tyler experienced gaming as less internally driven, engaged in it less often, had a less intense engagement and had low mastery-feelings about it. Tyler's interest in music was classified as a low flat interest: This interest was quite new to him and he gave it low scores on all scales. Tyler reported listening to music on several occasions and playing the drums and the piano once during a music lesson.

Tyler's interests in snowboarding and curriculum choices were both assigned to the irregular M-profile. Both interests were quite new to him, but he valued them highly, regarded them as quite internalized, engaged in them quite frequently and intensely, and had some mastery of these subjects. 
His interest in curriculum choices was very relevant to him: He had to make some curriculum choices at school soon and clarified in inTin that he thought these choices might determine the jobs he could apply for later. His new interest in snowboarding shows the same pattern on the dimensions. It seems that Tyler had an interest in sports in general, and despite being very novel the interest in snowboarding was regarded as internally driven and valuable.

Tyler's reported interests in watching television and reading a book were interests he had experienced for a while. These interests were assigned to the irregular W-profile: They were not valuable to him, he regarded them as quite externally supported, did not engage in them frequently or intensely, nor did he feel like he mastered these interests. Tyler watched television several times a week but did not find particular elements interesting about the programs he watched. He read a book on several occasions, but despite finding the topic interesting he did not value reading very highly.

\section{Discussion}

The current study aimed to clarify the structure of interest by investigating the relations between six dimensions as derived from the literature. We measured interests that high school students experienced in their daily lives to answer the following research question: What dimensional structure underlies the construct of interest in terms of the dimensions historicity, value, agency, frequency, intensity, and mastery?

Using a latent profile analysis we found evidence for a multidimensional structure of interests, as the latent profile analysis with four flat and two irregular patterns seemed to describe the data best. The flat profiles of interests indicate a homogeneous multidimensional structure: The scores on the six dimensions were approximately equal for interests with this pattern. However, the irregular patterns suggest a heterogeneous structure of interest where high scores on some dimensions go together with low scores on other dimensions. These patterns stress the importance of a multidimensional approach when investigating experiences of interest, both in scientific endeavors and educational contexts.

The homogeneous structure was most prevalent in the data. As the flat profiles in the six-profile model together contain $86 \%$ of the interests, it appears they demonstrate a typical structure of interest in which all the dimensions are rated equally high or low. For interests with this homogeneous structure, scores on the historicity-scale give an indication that high levels on the other dimensions have been established over time: A persistent interest generally has high levels on the dimensions and a new interest generally has low levels. This would also support the potential of situational interests in developing into more enduring interests, as suggested by Krapp (2002) and Hidi and Renninger (2006). However, as we did not investigate changes in the patterns of association over time, we can only speculate about this.

Even though many of the interests in the data conform to a homogeneous structure on the dimensions, the irregular profiles in LPA-models show more distinctive patterns of association between the dimensions. In the six-profile model two irregular patterns were identified. First, the M-profile contained new interests with a pattern of high attributed value and experienced intensity, a relatively internal agency, and medium levels on frequency and mastery. These interests are equally new as the interests in the low flat profile, but were rated much higher on all dimensions. The irregular M-profile interests might have developed very rapidly into interests that are important to the student, or the interest was considered valuable and internally controlled when the student first engaged in it. The notion of attributing high value to a relatively new interest has been discussed by Renninger (2000), though very briefly. She stated that a subset of interests consists of low knowledge and high potential value, which she calls attraction. Interests with such attraction over time may develop into an individual interest. However, Renninger does not elaborate on why the (potential) value of these interests is so high.

An explanation for the heterogeneous structure of the interests in the M-profile may lie in the concept of identification as used by Krapp (2002). Even if the psychological state of interest is initially triggered by environmental elements, the interests in the M-profile might show high compatibility with 
the identity, values, goals, or other interests of the person, which might cause the value, agency, and intensity of this interest to be very high. For example, the interests in the terrorist attacks in Paris that were assigned to the irregular M-profile might have been very relevant to the values and attitudes of these adolescents: They felt it was important to read and talk about this recent event. In the case of Tyler, curriculum choices are very relevant to the goal of finding a good job in due time, which makes it plausible that he values the interest in curriculum choices very highly. Tyler's new interests are related to his existing goals, which may cause him to identify with these interests rapidly (Hofer, 2010). Alternatively, the new interests are connected to existing individual interests, such as Tyler's interest in snowboarding and sports in general. This explanation is in line with Azevedo (2018) who states that situational interests might show continuities with previous experiences, which plays a role in their further development.

The interests with a W-pattern are interests that participants have had for a long time and show a pattern of low value, agency, frequency, mastery, and especially low levels of intensity: The experience of the person is not intense and they do not get absorbed when engaging with the interest. Within flow theory, the inverse of flow (intense engagement) is described as apathy or boredom, the result of low to moderate skills and low challenge. Nakamura and Csikszentmihalyi (2014) found that passive leisure activities and chores are commonly associated with apathy or boredom, which could provide an explanation for the large proportion of TV interest assigned to the irregular W-profile. The large portion of school interests in this profile might also be explained by flow theory: Students might have low skills and experience little challenge with regard to these interests, and feel boredom or apathy in relation to them. Nevertheless, although these interests might be regarded as boring, students still reported these activities or topics as interests.

A possible explanation for the pattern of $\mathrm{W}$-shaped interests comes from sociocultural theory, implying that interests are not always centered on the content but can also be a means to participate in a community one belongs to (Azevedo, 2006, 2018; DiGiacomo et al., 2018; Greeno, Collins, \& Resnick, 1996). Perhaps it is not the content of a W-shaped interest, but the participation in a community through this interest that makes the activity or topic interesting. For example, watching television at night with family might be interesting not necessarily because of the content of the program, but rather because it is a means to be part of the family. Alternatively, in the case of passive leisure interests, it could be that a person is not interested in an activity because of the content, but because of the effect that engaging with the interest has on one's mood and energy. Kleiber, Larson, and Csikszentmihalyi (2014) categorize watching television as a relaxed leisure activity, "a type of experience that may restore one's energy and spirit, but does not require exertion of effort" (p. 472). This restoration of energy might be exactly what makes the adolescents interested in this activity.

The findings of this study shed more light on how the dimensions underlying the four-phase model of interest development (Hidi \& Renninger, 2006) relate to one another in different interests. The flat patterns found are clearly represented in the four-phase model and seem very consistent with the descriptions of the four phases. The current study adds the irregular patterns to this model, which demonstrate more distinct ways in which the underlying dimensions can be interrelated. Where Hidi \& Renninger (2006) already expected some irregularities (e.g., by including 'typically though not exclusively' for some indicators), our results confirm and elaborate on these. It is recommended that future research investigates the complex interplay of dimensions in longitudinal studies in order to further address the relation of these patterns of interest to the developmental model.

It is important to bear in mind that the results of the current study relied on self-reported measurement, which required respondents to be aware of interests in order to report them. Renninger and Hidi (2016) state that "respondents in an early phase of interest development may not be in a position to respond to questions about the level of their interest; they may not be conscious that their interest has been triggered" (p. 62). However, the low flat profile provides evidence that participants were in fact able to report on their recently externally triggered interests. Providing the students with adequate instruction and keeping small, two-hour intervals between measurements has aided detection of externally triggered interests and put participants in a position to report on these. Another note of caution regarding the interpretation of the results could be the limited sample in terms of number and age. Even though the number of participants was relatively small $(n=94)$, data analysis was performed on the 
level of interests. As 1247 interests were reported, the sample size was deemed large enough to provide sufficient power for latent profile analysis (Tein, Coxe, \& Cham, 2013). Regarding the limited age range of the participants, one might argue that interest domains differ across age groups (e.g., Tracey, Robbins, \& Hofsess, 2005) and this might limit generalizability of the results. Even though we acknowledge that adolescents' interest domains change over time, we have no indication that the structure of interest is different across age groups (as also noted by Hidi \& Renninger, 2006). Moreover, the current study captured a wide variety of interests reflecting different domains of daily life, which makes it probable that we captured the comprehensive construct of interest.

The holistic and integrative approach of this study has allowed us to draw conclusions that can inform educational practice and interest research. With regard to school interests, we see multiple academic interests in all six profiles (though in varying quantities), and therefore the general conclusions of the study also yield for academic interests. The school interests categorized into the top and high flat profiles are especially relevant, as they challenge the generally held belief that students commonly lack individual interest in school subjects (as also found by Slot, Akkerman, \& Wubbels, 2019). As a consequence, educators might do well to determine the baseline subject-related interests of their students, in order to judge the necessity of triggering new, situational interest, or the possibility of appealing to existing, individual interests. The same goes for out-of-school interests, which can be important for study choices and hold learning potential (Holmegaard, 2015; Ito et al., 2018; Vulperhorst, van der Rijst, \& Akkerman, 2020). For example, research has shown that involving students' personal interests in school can improve homework completion rates, task interest and engagement (e.g., Hinton \& Kern, 1999; Reber, Canning, \& Harackiewicz, 2018). When assessing the interests of students, educators are advised to get a detailed understanding of the interest in terms of the dimensions, as for example the fact that an interest is very novel does not mean it is not important to the student (has high value). When educators gain a more detailed understanding of students' interests this can provide them with useful information about the students' out-of-school learning experiences, and avoid incorrect judgments about (the lack of) student interest. In addition, this study may help educators to identify students' potential and latent interests and to observe how these may vary before deciding upon a way to evoke or sustain students' interests in school. We propose more research into differences between (academic) interests assigned to the different profiles, for example in the object or educational context of these interests, to arrive at a better understanding of how to aid development of interests in classrooms.

With regard to interest research, the novel bottom-up approach of this study contributes to the field in several ways. Firstly, this study has demonstrated the necessity of measuring interests on multiple dimensions: Single indicators are not sufficient to measure the experience of interest due to its heterogeneity. Additionally, our findings suggest some additions to the developmental models of interest development so far (e.g., Hidi \& Renninger, 2006; Krapp, 2002), by demonstrating heterogeneous manifestations of interest. We do however stress that the fit indices in the current study were not conclusive on the exact number of interest variations in the data and the statistical support for our final model is not unambiguous. Hence we do not claim that these six patterns are the only potential profiles or manifestations of interest. We do however maintain that all found profiles are strikingly distinct in both shape and content, and that the irregular profiles are well interpretable and theoretically meaningful. Taken together this supports the notion of heterogeneity in manifestations of interest. We strongly recommend follow-up research to perform similar analyses on another dataset to confirm or refine these variations. To inform developmental models even more, we also recommend that researchers investigate the interplay of dimensions in a longitudinal manner to explicate multidimensional developmental relations, for example by using latent transitional modeling (LTA). This may reveal how interests within both homogeneous and heterogeneous profiles develop over time.

The findings of this study may help to understand and acknowledge the multidimensional experience of students' interests in educational settings. This multidimensionality calls for an idiosyncratic perspective on interest, focusing on the specific structure of every particular person-object relation. Only through this multidimensional structure we can fully grasp the powerful construct of interest and refine ways to evoke and sustain them in educational contexts. 


\section{Keypoints}

- Based on key scholars we identified six interest dimensions: historicity, value, agency, frequency, intensity, mastery

- Using these dimensions in LPA, a variety of interest manifestations is captured by latent profiles

- The profiles demonstrate both a homogeneous and heterogeneous structure of interest

- Interest measures should account for multidimensionality

\section{References}

Ainley, M., Hidi, S., \& Berndorff, D. (2002). Interest, learning, and the psychological processes that mediate their relationship. Journal of Educational Psychology, 94(3), 545-561. https://doi.org/10.1037//0022-0663.94.3.545

Akkerman, S. F., \& Bakker, A. (2012-2014). Interest in Science: Development across sites of learning. ELS Starting Grant, Utrecht University, the Netherlands.

Akkerman, S. F., \& Bakker, A. (2019). Persons pursuing multiple objects of interest in multiple contexts. European Journal of Psychology of Education, 34(1), 1-24. https://doi.org/10.1007/s10212-018-0400-2

Alexander, P. A., Kulikowich, J. M., \& Jetton, T. L. (1994). The role of subject-matter knowledge and interest in the processing of linear and nonlinear texts. Review of Educational Research, 64(2), 201252. https://doi.org/10.2307/1170694

Arnold, F. (1906). The psychology of interest (I). Psychological Review, 13(4), 221-238.

Asparouhouv, T., \& Muthén, B.O. (2007). Wald test of mean equality for potential latent class predictors in mixture modeling. Retrieved from http://www.statmodel.com/download/ MeanTest1.pdf on April 21, 2016.

Azevedo, F. S. (2006). Personal excursions: Investigating the dynamics of student engagement. International Journal of Computers for Mathematical Learning, 11, 57-98. https://doi.org/10.1007/s10758-0060007-6

Azevedo, F. S. (2018). An inquiry into the structure of situational interests. Science Education, 102(1), 108 127. https://doi.org/10.1002/sce.21319

Barron, B. (2006). Interest and self-sustained learning as catalysts of development: A learning ecology perspective. Human Development, 49(4), 193-224. https://doi.org/10.1159/000094368

Bruner, J. S. (1990). Acts of meaning. Cambridge, MA: Harvard University Press.

Csikszentmihalyi, M., \& Larson, R. (2014). Validity and reliability of the experience-sampling method. In M. Csikszentmihalyi (Ed.), Flow and the foundations of positive psychology (pp. 35-54). Dordrecht, The Netherlands: Springer.

Csikszentmihalyi, M., Larson, R., \& Prescott, S. (1977). The ecology of adolescent activity and experience. Journal of Youth and Adolescence, 6(3), 281-294. https://doi.org/10.1007/978-94-017-9094-9_12

Dewey, J. (1913). Interest and Effort in Education. Boston, MA: Houghton Mifflin.

DiGiacomo, D. K., Van Horne, K., Van Steenis, E., \& Penuel, W. R. (2018). The material and social constitution of interest. Learning, Culture and Social Interaction, 19, 51-60. https://doi.org/10.1016/j.lcsi.2018.04.010

Erstad, O., \& Silseth, K. (2019). Futuremaking and digital engagement: from everyday interests to educational trajectories. Mind, Culture, and Activity, 26(4), 309-322. https://doi.org/10.1080/10749039.2019.1646290

Greeno, J. G., Collins, A. M., \& Resnick, L. B. (1996). Cognition and learning. In D. Berliner \& R. Calfee (Eds.), Handbook of Educational Psychology (pp. 15-41). New York: MacMillian.

Harackiewicz, J. M., Barron, K. E., Tauer, J. M., \& Elliot, A. J. (2002). Predicting success in college: A longitudinal study of achievement goals and ability measures as predictors of interest and 
performance from freshman year through graduation. Journal of Educational Psychology, 94(3), 562-575. https://doi.org/10.1037/0022-0663.94.3.562

Harackiewicz, J. M., Durik, A. M., Barron, K. E., Linnenbrink-Garcia, L., \& Tauer, J. M. (2008). The role of achievement goals in the development of interest: Reciprocal relations between achievement goals, interest, and performance. Journal of Educational Psychology, 100(1), 105-122. https://doi.org/10.1037/0022-0663.100.1.105

Hedges, H. (2019). The "fullness of life": Learner interests and educational experiences. Learning, Culture and Social Interaction, 23. https://doi.org/10.1016/j.lcsi.2018.11.005

Hidi, S., \& Baird, W. (1986). Interestingness - A neglected variable in discourse processing. Cognitive Science, 10(2), 179-194. https://doi.org/10.1207/s15516709cog1002_3

Hidi, S., \& Renninger, K. A. (2006). The four-phase model of interest development. Educational Psychologist, 41(2), 111-127. https://doi.org/10.1207/s15326985ep4102_4

Hinton, L. M., \& Kern, L. (1999). Increasing homework completion by incorporating student interests. Journal of Positive Behavior Interventions, 1(4), 231-241. https://doi.org/10.1177/109830079900100405

Holmegaard, H. T. (2015). Performing a Choice-Narrative: A qualitative study of the patterns in STEM students' higher education choices. International Journal of Science Education, 37(9), 1454-1477. https://doi.org/10.1080/09500693.2015.1042940

Ito, M., Martin, C., Pfister, R. C., Rafalow, M. H., Salen, K., \& Wortman, A. (2018). Affinity online: How connection and shared interest fuel learning. NYU Press.

Kleiber, D., Larson, R., \& Csikszentmihalyi, M. (2014). The experience of leisure in adolescence. In M. Csikszentmihalyi (Ed.), Flow and the foundations of positive psychology (pp. 467-474). Dordrecht, The Netherlands: Springer.

Köller, O., Baumert, J., \& Schnabel, K. (2001). Does interest matter? The relationship between academic interest and achievement in mathematics. Journal for Research in Mathematics Education, 32(5), 448-470. https://doi.org/10.2307/749801

Krapp, A. (2002). Structural and dynamic aspects of interest development: Theoretical considerations from an ontogenetic perspective. Learning and Instruction, 12(4), 383-409. https://doi.org/10.1016/S0959-4752(01)00011-1

Krapp, A., Hidi, S., \& Renninger, K. A. (1992). Interest, learning, and development. In K. A. Renninger, S. Hidi, \& A. Krapp (Eds.), The role of interest in learning and development (pp. 3-25). Hillsdale, NJ: Lawrence Erlbaum Associates, Inc.

Lazarsfeld, P.F., \& Henry, N.W. (1968). Latent structure analysis. Boston: Houghton Mill.

Marsh, H. W., Lüdtke, O., Trautwein, U., \& Morin, A. J. (2009). Classical latent profile analysis of academic self-concept dimensions: Synergy of person-and variable-centered approaches to theoretical models of self-concept. Structural Equation Modeling: A Multidisciplinary Journal, 16(2), 191-225. https://doi.org/10.2307/30047170

Meeus, W., Van De Schoot, R., Keijsers, L., Schwartz, S. J., \& Branje, S. (2010). On the progression and stability of adolescent identity formation: A five-wave longitudinal study in early-to-middle and middle-to-late adolescence. Child development, 81(5), 1565-1581. https://doi.org/10.1111/j.14678624.2010.01492.x

Mitchell, M. (1993). Situational interest: Its multifaceted structure in the secondary school mathematics classroom. Journal of Educational Psychology, 85(3), 424-436. https://doi.org/10.1037/00220663.85.3.424

Muthén, L.K., \& Muthén, B.O. (2015). Mplus User's Guide. 7th Ed. Los Angeles, CA: Muthén \& Muthén.

Nakamura, J., \& Csikszentmihalyi, M. (2014). The concept of flow. In M. Csikszentmihalyi (Ed.), Flow and the foundations of positive psychology (pp. 239-263). Dordrecht, The Netherlands: Springer.

Reber, R., Canning, E. A., \& Harackiewicz, J. M. (2018). Personalized education to increase interest. Current Directions in Psychological Science, 27(6), 449-454. https://doi.org/10.1177/0963721418793140

Renninger, K. A. (2000). Individual interest and its implications for understanding intrinsic motivation. In C. Sansone \& J. M. Harackiewicz (Eds.), Intrinsic and extrinsic motivation: The search for optimal motivation and performance (pp. 373-404). New York, NY: Academic Press. 
Renninger, K. A., Bachrach, J. E., \& Hidi, S. E. (2019). Triggering and maintaining interest in early phases of interest development. Learning, Culture and Social Interaction, 23, 100260. https://doi-org /10.1016/j.lcsi.2018.11.007

Renninger, K. A. \& Hidi, S. (2016). The power of interest for motivation and engagement. New York, NY: Routledge.

Renninger, K. A., \& Leckrone, T. (1991). Continuity in young children's actions: A consideration of interest and temperament. In L. Oppenheimer \& J. Valsiner (Eds.), The origins of action: Interdisciplinary and international perspectives (pp. 205-238). New York, NY: Springer-Verlag.

Renninger, K. A., \& Su, S. (2019). Interest and Its Development, Revisited. In R. M. Ryan (Ed.), The Oxford Handbook of Human Motivation (pp. 205-225). Oxford, England: Oxford University Press.

Sachisthal, M. S. M., Jansen, B. R. J., Peetsma, T. T. D., Dalege, J., van der Maas, H. L. J., \& Raijmakers, M. E. J. (2019). Introducing a science interest network model to reveal country differences. Journal of Educational Psychology, 111(6), 1063-1080. https://doi.org/10.1037/edu0000327

Schiefele, U. (1992). Topic Interest and Levels of Text Comprehension. In K. A. Renninger, S. Hidi, \& A. Krapp (Eds.), The role of interest in learning and development (pp. 151-182). Hillsdale, NJ: Lawrence Erlbaum.

Schiefele, U. (2009). Situational and individual interest. In K. Wentzel, A. Wigfield, \& D. Miele (Eds.), Handbook of motivation at school (pp. 197-222). New York, NY: Routledge.

Schiefele, U., Krapp, A., \& Winteler, A. (1992). Interest as a predictor of academic achievement: A metaanalysis of research. In K. A. Renninger, S. Hidi, \& A. Krapp (Eds.), The role of interest in learning and development (pp. 183-212). Hillsdale, NJ: Lawrence Erlbaum.

Schiefele, U. \& Rheinberg, F. (1997). Motivation and knowledge acquisition: Searching for mediating processes. In M. L. Maehr \& P. R. Pintrich (Eds.), Advances in motivation and achievement, Volume 10 (pp. 251-301). Greenwich, UK: JAI Press.

Slot, E., Akkerman, S., \& Wubbels, T. (2019). Adolescents' interest experience in daily life in and across family and peer contexts. European Journal of Psychology of Education, 34(1), 25-43. https://doi.org/10.1007/s10212-018-0372-2

Strong, E. K., (1927). Vocational interest test. Educational Record, 8, 107-121.

Tein, J. Y., Coxe, S., \& Cham, H. (2013). Statistical power to detect the correct number of classes in latent profile analysis. Structural Equation Modeling: A Multidisciplinary Journal, 20(4), 640-657. https://doi.org/10.1080/10705511.2013.824781

Tobias, S. (1994). Interest, prior knowledge, and learning. Review of Educational Research, 64(1), 37-54. https://doi.org/10.3102/00346543064001037

Tracey, T. J., Robbins, S. B., \& Hofsess, C. D. (2005). Stability and change in interests: A longitudinal study of adolescents from grades 8 through 12. Journal of Vocational Behavior, 66(1), 1-25. https://doi.org/10.1016/j.jvb.2003.11.002

Vulperhorst, J. P., van der Rijst, R. M., \& Akkerman, S. F. (2020). Dynamics in higher education choice: weighing one's multiple interests in light of available programmes. Higher Education, 79, 10011021. https://doi.org/10.1007/s10734-019-00452-x

Walkington, C. A. (2013). Using adaptive learning technologies to personalize instruction to student interests: The impact of relevant contexts on performance and learning outcomes. Journal of Educational Psychology, 105(4), 932-945. https://doi.org/10.1037/a0031882 


\section{Appendix}

\section{5-dimension model excluding historicity}

Table A. 1

Log-Likelihood, Model Fit Indices and Entropy Measures for the 1- to 7-Profile Models Excluding Historicity $(N=1247)$.

\begin{tabular}{l|lllll:l|l|l|}
\hline & 1-p LPA & 2-p LPA & 3-p LPA & 4-p LPA & 5-p LPA & 6-p LPA & 7-p LPA \\
\hline LLH & -28647.899 & -27859.979 & -27640.820 & -27570.601 & -27499.029 & -27419.672 & -27360.114 \\
AIC & 57315.798 & 55751.957 & 55325.640 & 55197.202 & 55066.058 & 54919.343 & 54812.228 \\
BIC & 57367.083 & 55834.018 & 55438.467 & 55340.800 & 55240.426 & 55124.483 & 55048.139 \\
adj BIC & 57335.318 & 55783.190 & 55368.585 & 55251.859 & 55132.427 & 54997.425 & 54902.022 \\
\hline Entropy & n/a & 0.798 & 0.811 & 0.745 & 0.789 & 0.822 & 0.822 \\
\hline
\end{tabular}

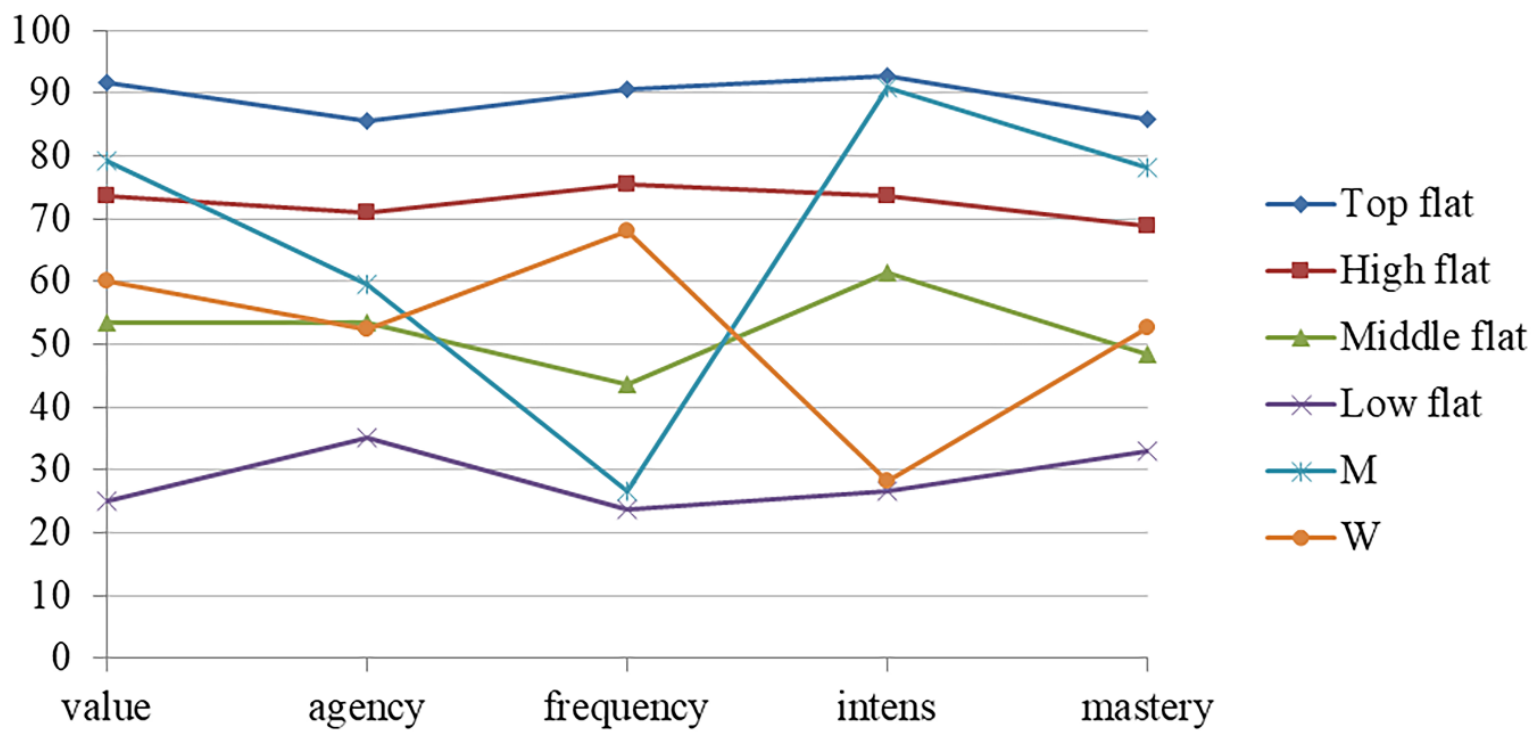

Figure A.1. Profiles in the six-profile solution. 